\title{
How to Manage Complications Related to the Use of Intramedullary Screws in Metacarpal Fractures: Case Series
}

\section{Cómo resolver las complicaciones relacionadas al uso de tornillos intramedulares en fracturas de metacarpianos: serie de casos}

\author{
Eliana Camacho ${ }^{1,2}$ Matías Craviotto ${ }^{1,2}$ Lucía D’Oliveira ${ }^{1,2}$
}

${ }^{1}$ Esthetic and Reconstructive Plastic Surgery Service, Hospital de Clínicas, Montevideo, Uruguay

2 Plastic Surgery Department, Hospital Central de las Fuerzas Armadas, Montevideo, Uruguay

Rev Iberam Cir Mano 2021;49:4-12
Address for correspondence Eliana Camacho García, calle Pedro Manini Rios 6065 BIS, Montevideo, 11500, Uruguay (e-mail: elianacamachogarcia@gmail.com).

\begin{abstract}
Keywords

- metacarpal

- fracture

- intramedullary screw

- complications

The use of intramedullary screws has been increasing among hand surgeons in cases of metacarpal fractures due to their low morbidity, and because they minimize incisions and dissection, and require less tissue manipulation and deperiostization. However, there are few published articles on the complications that arise from its use. Therefore, the purpose of the current study is to present a series of cases of complications following the use of intramedullary screws in metacarpal fractures that required surgical intervention, and to describe the surgical technique used to solve them .

Methods We performed a retrospective multicenter study in which we reviewed the clinical history, surgical descriptions and radiographs of the patients submitted to fixation of intramedullary compression screws for metacarpal fractures. We defined as complications infection, lesion to the extensor apparatus, bending of the implant, loss of reduction, hardware failure, malrotation, and non-union.

Results Out of a total of 45 patients, we reported 3 cases of complication: 1 patient with loss of reduction, and 2 patients with bending of the implant. In the three cases, the screw was removed without complications, and the focus of the fracture was stabilized.

Conclusion Intramedullary fixation with compression screws is increasingly being used for metacarpal fractures, with reports of low rates of complications. In the series of cases herein reported, the complications were solved without difficulty, and the patients showed a good recovery in hand function in the follow-up. Knowledge of the possible complications and their management enables us to provide more safety to the patient at the time of choosing this technique.
\end{abstract}

received

July 1,2020

accepted after revision

December 1, 2020
DOI https://doi.org/ $10.1055 / \mathrm{s}-0041-1730001$ ISSN 1698-8396.

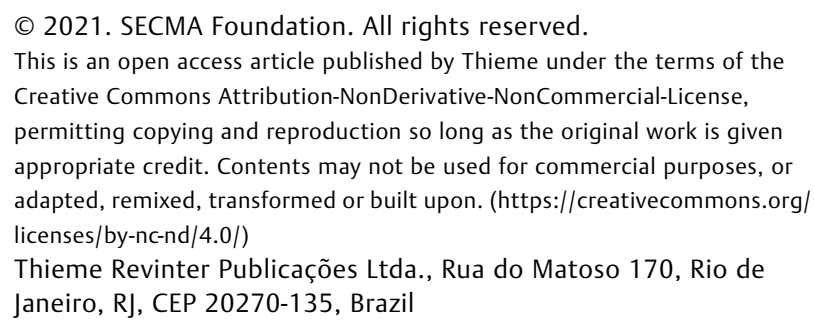
appropriate credit. Contents may not be used for commercial purposes, or adapted, remixed, transformed or built upon. (https://creativecommons.org/ licenses/by-nc-nd/4.0/) Thieme Revinter Publicações Ltda., Rua do Matoso 170, Rio de Janeiro, RJ, CEP 20270-135, Brazil 


\section{Resumen}

\author{
Palabras clave \\ - metacarpiano \\ - fractura \\ - tornillo intramedular \\ - complicaciones
}

Los tornillos intramedulares son cada vez más utilizados por los cirujanos de mano en fracturas de metacarpianos dada su baja morbilidad, pues minimizan las incisiones, la disección, y requieren una menor manipulación de tendones y desperiostización. Sin embargo, son pocos los artículos publicados que se dedican a las complicaciones que surgen de su uso. Por lo tanto, el objetivo de este trabajo es presentar una serie de casos de complicaciones, ocurridas luego del uso de tornillos intramedulares en fracturas de metacarpianos, que requirieron una reintervención quirúrgica, así como describir la técnica utilizada para solucionar dichas complicaciones.

Métodos Se realizó un estudio descriptivo, retrospectivo, multicéntrico, en que se revisaron las historias clínicas, descripciones operatorias y radiografías de los pacientes que se sometieron a enclavijado intramedular con tornillos compresivos para fracturas de metacarpianos. Definimos como complicaciones infección, lesión del aparato extensor, doblamiento del implante, pérdida de reducción, rotura del implante, malrotación, y no unión.

Resultados Se reportaron 3 complicaciones de un total de 45 pacientes. Una de las complicaciones fue pérdida de reducción, y las otras dos, doblamiento del implante. En los tres pacientes se realizó retiro el tornillo sin complicaciones, y se estabilizó el foco de fractura.

Conclusión El enclavijado endomedular con tornillos compresivos es cada vez más utilizado en fracturas de metacarpianos, y se reporta una baja tasa de complicaciones. En la serie de casos presentada, éstas fueron resueltas sin dificultades, y los pacientes lograron una buena función de la mano en el seguimiento postoperatorio. El conocimiento de las posibles complicaciones y su manejo permite brindar mayor seguridad al paciente a la hora de elegir esta técnica.

\section{Introduction}

Metacarpal fractures are a frequent reason for visits to the plastic surgery practice. These hand injuries are the most frequent lesions to the upper limbs, constituting $10 \%$ of all body fractures, and $18 \%$ to $44 \%$ of all hand fractures. ${ }^{1-4}$

Metacarpal fractures are more frequent in men, and they reach their maximum incidence in patients aged between 10 and 40 years; therefore, these injuries interfere with labor activities, with important consequences. ${ }^{5}$

Most of these fractures are single, simple, closed, stable injuries. Orthopedic treatment results in excellent outcomes in many cases, ${ }^{5}$ while other cases require sophisticated surgical techniques. Controversies surround different treatment algorithms. ${ }^{4,6}$

It is accepted that any degree of rotational deformation is an indication for surgical treatment. Additional indications include bone shortening $>5 \mathrm{~mm}$, a bone step $>1 \mathrm{~mm}$ at the articular surface, or articular surface involvement $>25 \%$. Adjacent metacarpal fractures can result in a surgical indication due to the loss of their stabilizing effect. $^{2}$

Intramedullary screws are a relatively recent, fast, lowmorbidity option related to reduced incisions, dissection, and manipulation of the tendon and periosteum. As such, they are increasingly being used by hand surgeons. Their indications include closed fractures, with short transverse and oblique lines. These screws enable safe stabilization, with early rehabilitation as an advantage. ${ }^{7}$

Although the literature detailing this surgical technique and its outcomes is rich, few articles are devoted to its complications and their treatment.

\section{Objective}

The present study aims to present a case series of complications related to intramedullary screws in metacarpal fractures which required surgical reinterventions, and to describe the technique used to solve these intercurrences.

\section{Materials and Methods}

Study type: a multicenter, retrospective, descriptive study based on medical records of patients operated on for metacarpal fractures using intramedullary screws for stabilization from 2016 to 2019.

Medical records, surgical descriptions, and radiographs were reviewed with the previous consent of the patients.

The inclusion criteria were patients operated on for metacarpal fractures stabilized with intramedullary nails and screws. Subjects who did not sign the informed consent 
form or with no complete photographic record were excluded from the study.

Personal data, implant type, and complications and their sequela were recorded.

The complications included infection, injury to the extensor apparatus, implant bending, loss of reduction, implant rupture, malrotation, and non-union. The patient were followed up from 2 months to 3 years after surgery, with a mean follow-up of 6 months.

The patients were assessed after reoperation regarding the range of motion of the metacarpophalangeal joint and the clinical and radiological consolidation of the fracture.

\section{Results}

A total of 3 complications were reported in 45 patients with metacarpal fractures submitted to surgical treatment. The mean age of the patients with complications was 23 years; none of them had a personal history of note. In two cases, the fracture occurred in the dominant (right) hand, whereas in the third case it affected the non-dominant (left) hand. The third metacarpal bone was injured in the first case; in the second case, the fourth metacarpal bone; and, in the third case, the fifth metacarpal bone. All three cases were isolated injuries due to direct trauma to the hand. Two cases presented a mid-diaphyseal fracture of transverse geometry, and the third case was a mid-diaphyseal fracture of short oblique geometry.

In all three cases, intramedullary headless compression screws (HCSs, Depuy Synthes, Raynham, MA , US) with $3.0 \mathrm{~mm}$ in diameter and $40 \mathrm{~mm}$ in length were used. The same surgical technique was used in all cases, with retrograde intramedullary nailing through a longitudinal approach of the extensor apparatus at the level of the metacarpal head. A cotton-padded, compressive bandage was used for two weeks to reduce the edema and begin mobilization in a protected way.

None of these cases involved surgical-site infection, malrotation, non-union, extensor apparatus injury, or rigidity of the metacarpophalangeal joint.

Among the three reported complications, one patient had loss of fracture reduction, and two patients presented screw bending (- Figure 1).

The first case is that of a 31-year-old man, who was healthy, right-handed, and presented a closed fracture at the third metacarpal bone due to crushing caused by machinery. The fracture consisted of a single line of short oblique geometry. An intramedullary screw with $3.0 \mathrm{~mm}$ in diameter and $40 \mathrm{~mm}$ in length was placed. The first postoperative physical examination revealed a bony protrusion and intense pain on palpation at the operated metacarpal bone. A control radiograph showed loss of fracture reduction, so we decided for a reintervention. At first, our intention was to perform closed reduction with screw extraction through the initial approach but this was not possible; therefore, the fracture was openly reduced. After the alignment of the fracture, we tried to extract the screw through the metacarpal head, cannulating it, with no success. Therefore, the screw was advanced proximally, until its head was visualized at the fracture line, and then extracted. The fracture was stabilized with the compression-screw technique (-Figure $\mathbf{1}$ ). The patient presented a favorable evolution with rehabilitation, achieving complete range of motion of the metacarpophalangeal joint, from $0^{\circ}$ to $90^{\circ}$. Clinical consolidation and radiological consolidation of the fracture site were observed 4 and 6 weeks after the reintervention respectively. The patient resumed his work activities 4 weeks after surgery (-Figure $\mathbf{2}$ ).

The other two patients presented with pain and edema on the fracture site after a new trauma to the operated ray. Radiographs revealed implant bending. The first patient suffered trauma a month after surgery, and the second patient sustained it two months after surgery. Before the trauma, both subjects presented clinical and radiological consolidation, and resumed their usual activities. A new surgery was performed using the previous approach, with implant extraction through the metacarpal head, with no intercurrences. In both cases, the fracture site was stabilized with an intramedullary screw with $3.0 \mathrm{~mm}$ in diameter and $40 \mathrm{~mm}$ in length. Both patients presented good postoperative rehabilitation, achieving clinical consolidation at four weeks, and then resuming their usual activities. Full range of motion of the metacarpophalangeal joint was achieved, from $0^{\circ}$ to $90^{\circ}$ degrees (-Figures 2-3).

\section{Surgical Technique}

The 3 patients were submitted to surgery under general anesthesia; a bloodless field was maintained with a pneumatic cuff inflated at $100 \mathrm{~mm} \mathrm{Hg}$ above the systemic arterial pressure. The previous approach was used over the scar, and then a longitudinal tenotomy was performed on the extensor apparatus. Screw cannulation was achieved with a \#18 intravenous catheter mandrel, in an attempt to introduce it through the metacarpal head at the site with the previous intramedullary screw. In all three cases, the previous approach site was found with no difficulty at the metacarpal head; it was filled with easily-removable fibrous tissue, and promptly crossed with the intravenous device. The mandrel was also used to clean the screw head of cellular debris, providing access to the screwdriver. The position of the device was checked with intraoperative fluoroscopy, and then the screw was cannulated and easily removed with the screwdriver. In the first case, cannulation was not achieved, requiring screw advancement towards the fracture site; the screw was removed after its head was visualized. In both patients with screw bending, extraction through the previous approach was not difficult. We wondered if the screw could be removed if its bending angle had been greater.

We find it interesting to demonstrate the technique used to find the screw path with an intravenous catheter, which is an accessible, inexpensive device available in all health centers (-Figure $\mathbf{3}$ ). 

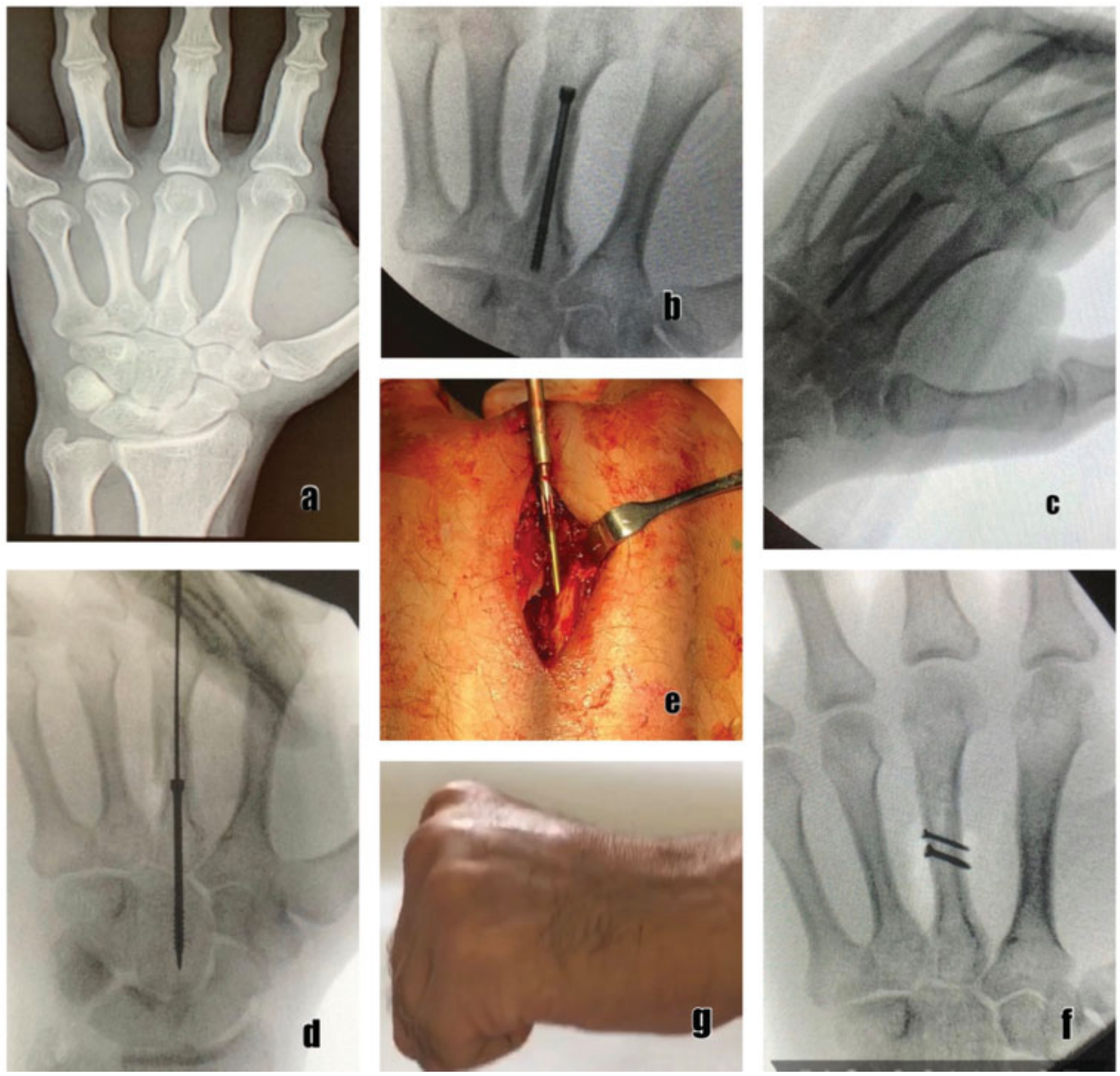

Fig. 1 (A) Displaced single fracture at the third metacarpal bone, with a short oblique line. (B) Closed reduction was performed using intramedullary screws (3.0-mm in diameter, $40-\mathrm{mm}$ in length); the image shows the reduction achieved during surgery. (C) Radiograph of the first postoperative control, one week later, revealing loss of reduction. (D) Intraoperative image showing proximal advancement of the screw for its extraction through the fracture site, since it was not possible to do it through the metacarpal head. (E) Intraoperative image showing screw extraction through the fracture site. (F) Intraoperative image showing the reduction achieved using compression screws. (G) Function four weeks after surgery, with total flexion of the metacarpophalangeal joint.

\section{Discussion}

The clinical guidelines agree that more distal and/or ulnar metacarpal fractures are well-tolerated and may not require surgery. Diaphyseal fractures of the second and third fingers can tolerate up to $20^{\circ}$ of angulation, whereas the fourth and fifth fingers can tolerate $30^{\circ}$ and $40^{\circ}$ respectively. ${ }^{1,5}$

Surgical techniques that involve an intramedullary device are not new; they were described 40 years ago by Guy Foucher, who reported an intramedullary fixation technique using 2 or three 3 Kirschner wires in an antegrade manner, leaving them subcutaneously for subsequent removal at 6 to 8 weeks. $^{8}$

In osteoarticular surgery, intramedullary screws are beneficial to long-bone fractures for several reasons. The dissection of soft tissue is minimal, far from the fracture site, enabling the preservation of the hematoma and periosteum at the fracture site. In addition, it enables early mobilization, with a high rate of union. ${ }^{1,8}$

In 2015, Del Piñal et al. ${ }^{7}$ published the technique applied to metacarpal and phalangeal bone fractures, which is described for closed, transverse, or short oblique fractures with 

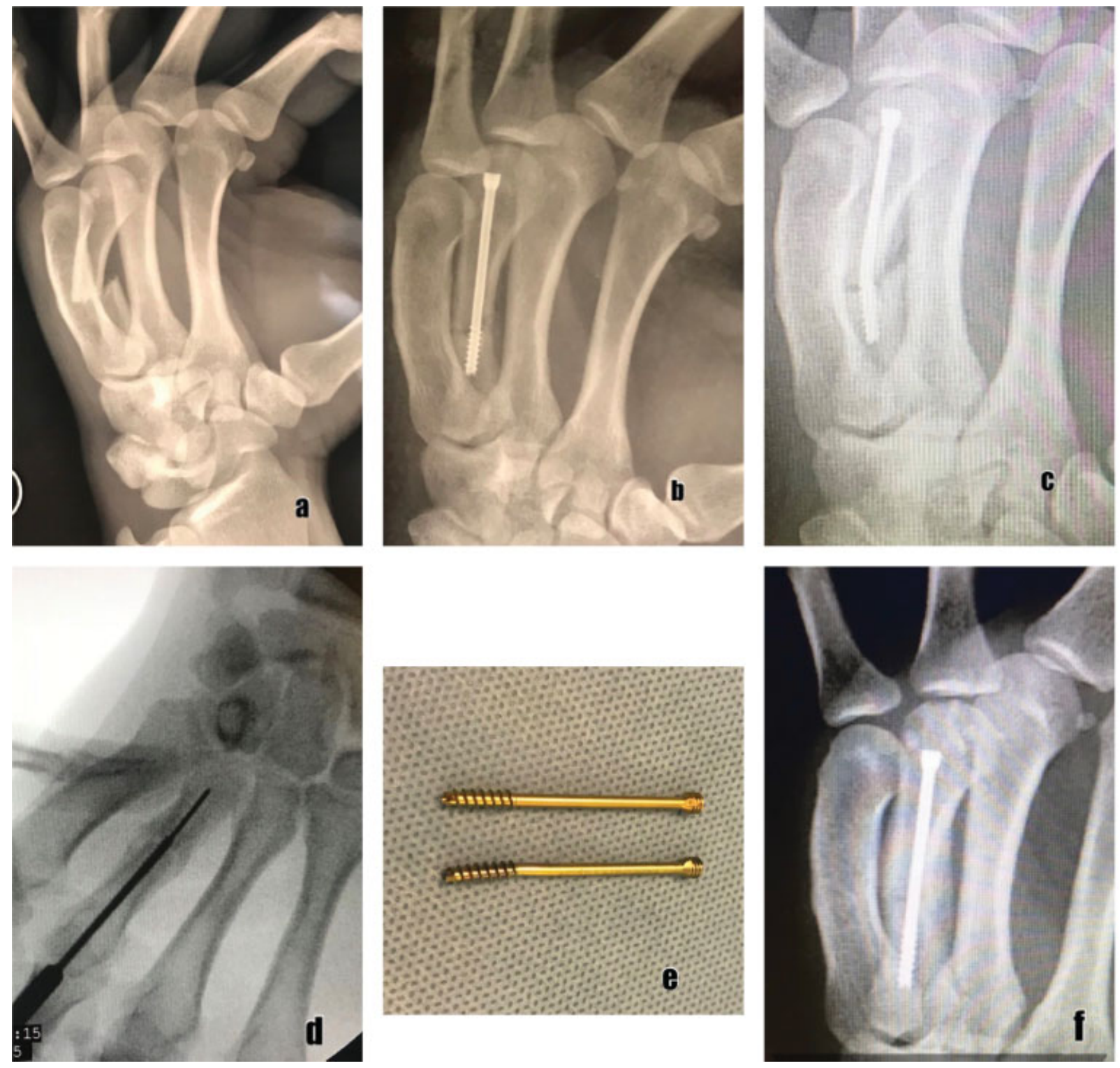

Fig. 2 (A) Preoperative image showing a single mid-diaphyseal fracture of the fourth metacarpal bone with a displaced transverse line. (B) Image showing consolidation of the fracture focus five weeks after surgery. (C) Image showing implant bending and posttrauma focal refracture eight weeks after surgery. (D) Intraoperative image showing screw extraction through the metacarpal head. (E) Bending of the removed implant. (F) Postoperative control at six weeks showing consolidation of the fracture site and the properly-positioned implant. (Photo of a patient from Hospital Central de las Fuerzas Armadas, Montevideo, Uruguay, who consented to its use.)

minimal comminution. The advantages of the use of intramedullary screws in these fractures include a relatively fast technique, with minimal soft-tissue dissection, and good focal stability, enabling early joint mobility. In addition, since these are intramedullary implants, there is no risk of devicerelated irritation. ${ }^{1,3}$

Absolute contraindications for the technique described by these authors include infection or open epiphyses. Intramedullary screws are not recommended for long oblique fractures, or when cortical continuity cannot be reestablished in diaphyseal fractures, since screw insertion results in collapse. In addition, these authors recommend care when using this technique in marginal fractures. ${ }^{7}$

Although intra-articular screws are criticized for violating the articular cartilage, they are used routinely to fixate upper-limb fractures, including those at the scaphoid, radial head, and humeral condyle, with no long-term clinical consequences. ${ }^{9}$

A quantitative analysis ${ }^{10}$ of the extension of the articular surface at the level of the metacarpal head that was affected by this technique was performed using tomography and three-dimensional reconstruction. Joint involvement at the level of the metacarpal head was calculated using headless 

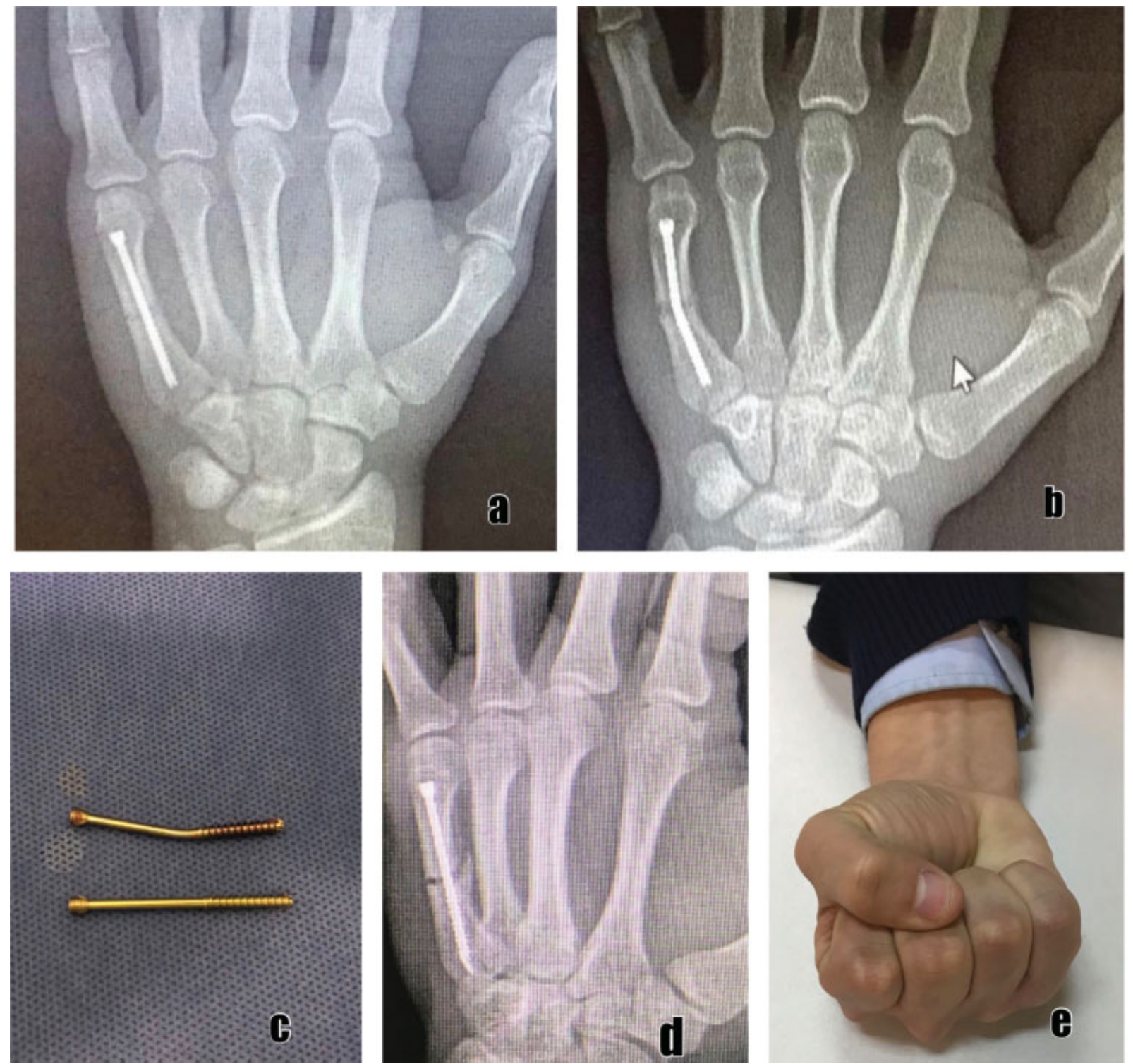

Fig. 3 (A) Four weeks after surgery, the implant is properly positioned, and focal consolidation is ongoing. (B) Radiograph five months after surgery showing implant bending following a trauma at the same ray. (C) Intraoperative image after implant removal, showing its bending. (D) Postoperative image showing adequate implant placement and proper bone alignment. (E) Four weeks after the new surgery, complete flexion of the metacarpophalangeal joint is observed on the assessment of hand function. (Photo of a patient from Hospital Central de las Fuerzas Armadas, Montevideo, Uruguay, who consented to its use.)

intramedullary screws in comparison with Kirschner wires. The analysis revealed that 2.4-mm and 3.0-mm screws occupied $4 \%$ and $5 \%$ of the joint respectively. In comparison to these screws, 1.1-mm Kirschner wires occupy an articular surface 10 -fold smaller. The authors also found that the dorsal entry of the screw at the medullary canal is not in line with the center of the articular base in the first phalanx in most of the sagittal plane. ${ }^{10}$ The patients presented no alterations at the metacarpophalangeal joint, with excellent joint function after surgery, despite screw entry at the level of the metacarpal head. Other studies ${ }^{4,5,7,9,11,12}$ describe excellent outcomes with this technique.
In 2014, Rulchesman et al. ${ }^{11}$ followed up 20 patients for 3 months after surgery. All subjects demonstrated complete mobility of the metacarpophalangeal joint in both flexion and extension. The mean grip strength was of $105 \%$ compared to the contralateral hand. All patients presented radiographic union at 6 weeks. No secondary surgeries were required. Two patients suffered a new fracture at the metacarpal shaft due to a new high-energy trauma. They were submitted to screw removal followed by open reduction and fixation with stable osteosynthesis. No cases of osteoarthritis or chondrolysis were observed on radiographs during the follow-up. 
In a paper published in 2015, Doarn et al. ${ }^{5}$ analyzed the short-term outcomes of the use of intramedullary screws in displaced fractures at the fifth metacarpal bone neck. This was a retrospective study based on medical records from 10 patients followed up for a mean period of 36 weeks. The mean radiographic time of consolidation was of 5 weeks, and anatomical reduction was achieved in all cases. The mean time to resume work activities was of 6 weeks. These authors reported a range of mobility of the metacarpophalangeal joint from $0^{\circ}$ to $90^{\circ}$, with a grip strength equal to that of the contralateral hand, and no treatment-related complications.

In 2016, Tobert et al. $^{9}$ published a retrospective review conducted at the Massachusetts Hospital and based on medical records from patients submitted to the intramedullary screw technique from 2007 to 2015 . In total, there were 18 metacarpal fractures in 16 patients. The mean follow-up was of ten weeks. The patients presented excellent outcomes, with a total range of motion $>240^{\circ}$. No complications were recorded during the follow-up. A patient presented a new trauma 19 months after surgery, which resulted in intramedullary nail bending observed on the radiographs; however, this subject had no pain and presented a full range of motion at the affected finger.

In 2015, Del Piñal et al. ${ }^{7}$ published a retrospective work analyzing medical records and radiographs of patients treated with intramedullary screws for hand fractures, including those to the metacarpal and phalangeal bones, over a 5-year period. In total, 69 fractures were treated in 59 subjects. The patients resumed their work activities after an average period of 76 days. The postoperative range of motion was of $247^{\circ}$, except in 2 subjects, who also presented tendon injuries. All patients presented fracture consolidation at the last follow-up, some with exuberant callus, and others with minimal callus. In two patients with four metacarpal fractures, the surgical technique was abandoned intraoperatively due to excessive comminution which could not be controlled with screws.

In 2019, Eisenberg et al. ${ }^{4}$ published a retrospective study based on the review of medical records of patients undergoing fixation of the metacarpal neck and diaphysis fractures with intramedullary screws. The review was conducted from 2010 to 2017, and included 91 patients. All patients achieved full digital flexion, with a full range of motion at the level of the metacarpophalangeal joint. Grip strength was assessed in 52 patients, and it reached 104.1\% compared to the contralateral hand. Radiographic consolidation was evaluated in 86 patients with a rate of union of 76\% after 6 weeks. Regarding clinical consolidation, all patients were using the hand with no restriction at 6 weeks. As for the complications, they reported three cases of refracture after a new trauma; these patients had previously achieved complete fracture healing. The screw was removed through the fracture site, and osteosynthesis with plates and screws was performed.

Still in 2019, in a retrospective review, Warrender et al. ${ }^{12}$ evaluated the complications after surgery with intramedullary screws. In total, 4 complications were reported out of 160 metacarpal fractures. None of the patients had malrotation, non-union, delayed union, stiffness of the metacarpophalangeal joint, or infection. One of these complications was an allergy to the implant 2 weeks postsurgery; the screw was removed 3 months after the procedure, with no sequelae. Another patient had implant rupture after a new trauma ten months after surgery; the screw was removed, and a new osteosynthesis with plates and screws was performed. The two remaining patients presented with bent implants; one of them had repeated trauma to the surgical area six months after surgery. Screw removal and osteosynthesis with plates and screws were performed on the refractured metacarpal bone. The other patient underwent a radiological control at 18 months which revealed the bent screw; however, as he was completely asymptomatic and the fracture was consolidated, the screw was left in place. This review ${ }^{12}$ reported a $2.5 \%$ complication rate.

The rate of complications from the aforementioned study $^{12}$ is consistent with our findings. Neither article reported infection, malrotation, joint stiffness, non-union, or delayed union.

In different studies, ${ }^{4,9,11,12}$ the most reported complication is a refracture of the affected ray with implant bending after a new trauma, which is consistent with our casuistry.

Comparing this surgical method to the available techniques, Avery et al. ${ }^{1}$ carried out a biomechanical study to determine the stability of intramedullary screws versus Kirschner wires to fixate fractures at the level of the metacarpal bone neck. These authors showed that, although these two methods resulted in similar stiffness, the maximum load supported by the implant is significantly higher for intramedullary screws, both for 3-point bending and axial load. As such, they concluded that intramedullary screws provide excellent biomechanical stability in this type of fracture.

In 2019, Oh et al. ${ }^{13}$ compared the biomechanical features of Kirschner wires, intramedullary screws, and plates with screws in metacarpal fractures in cadaveric material. They compared the tensile forces and concluded that plates and screws were the most stable method, resulting in implant bending with a peak load of $246 \mathrm{~N}$, followed by intramedullary screws, with $181 \mathrm{~N}$, and Kirschner wires, with $134.6 \mathrm{~N}$. However, this study ${ }^{13}$ employed a single Kirschner wire, which is unusual in metacarpal fractures fixation.

The patients must be informed about the possibility of refractures with implant bending or rupture in the case of a new hand trauma, which will require screw extraction, and, therefore, a new surgical intervention.

A comparison of complication rates from intramedullary screws and other techniques for metacarpal fractures reveals promising results. Kirschner wires are widely used in these fractures with the advantage of minimal soft-tissue manipulation; however, their lower stability requires postoperative immobilization, increasing the risk of joint contracture. 
In addition, infection of the wire path is one of the most frequent complications, with rates of up to $5.1 \%{ }^{14}$ this complication was not reported in the different studies herein analyzed or in our case series.

Open reduction and internal fixation with plates and screws provides the greatest stability, enabling early mobilization. However, it requires greater soft-tissue dissection, increasing the risk of fibrosis and adhesions. ${ }^{13,15}$ In a metaanalysis published in 2017, Melamed et al. ${ }^{16}$ compared fixation with plates and screws to percutaneous pinning in metacarpal fractures. They concluded that pinning resulted in greater joint-mobility scores when compared to plates and screws, but with no significant differences regarding grip strength, consolidation time, and complication rates.

The surgical technique for screw extraction may be difficult. One needs to be prepared to perform an open approach when extracting the screw through the fracture site. In cases in which screw cannulation through the original approach is successful, extraction is easier and far from the fracture focus. Although our series had no cases of implant ruptures, Warrender et al., ${ }^{12}$ in their paper discussing technical complications, reported that screw extraction can be a challenge in these ruptures, requiring a two-part process: the distal end of the screw is removed through the original approach, and the proximal end is removed through the fracture site.

Even though several articles discuss the outcomes of this surgical technique, few address the complications related to it. It is critical to analyze such complications because this technique has become one of the most widely used tools in cases of hand fracture. Knowing the potential complications and their management increases the safety of the patients submitted to this technique.

Our clinical cases made us wonder what would happen if the bending angle of the screws had been greater. Would implant removal be feasible? How would it be achieved? These questions are not answered by the literature, and that is why we believe it is vital to report and publish complications, not only to solve these doubts but to guide other colleagues facing them.

The limitations to our study include its retrospective design, and the fact that only short-term complications were addressed.

\section{Conclusion}

Based on our findings, we conclude that intramedullary screws are a reliable technique, with good outcomes in the treatment of metacarpal fractures.

To avoid certain complications, it is important to strictly adhere to the indications of this technique, such as achieving a good balance of the length of the screws on each side of the line, and to use them in fractures of transverse or short oblique geometry.

Given the recent nature of this technique, it is to be expected that the number of publications on complications will be lower compared to classic stabilization methods. It is important for surgeons using this technique to follow-up their patients and publish the short- and long-term complications to define the full spectrum of possibilities following the placement of intramedullary screws and how to solve them.

\section{Conflict of Interests}

The authors have no conflict of interests to declare.

\section{References}

1 Avery DM III, Klinge S, Dyrna F, et al. Headless Compression Screw Versus Kirschner Wire Fixation for Metacarpal Neck Fractures: A Biomechanical Study. J Hand Surg Am 2017;42(05):392.e1-392. e6. Doi: 10.1016/j.jhsa.2017.02.013

2 Wong VW, Higgins JP. Evidence-Based Medicine: Management of Metacarpal Fractures. Plast Reconstr Surg 2017;140(01):140e-151e. Doi: 10.1097/PRS.0000000000003470

3 Jann D, Calcagni M, Giovanoli P, Giesen T. Retrograde fixation of metacarpal fractures with intramedullary cannulated headless compression screws. Hand Surg Rehabil 2018;37(02):99-103. Doi: 10.1016/j.hansur.2017.12.005

4 Eisenberg G, Clain JB, Feinberg-Zadek N, et al. Clinical Outcomes of Limited Open Intramedullary Headless Screw Fixation of Metacarpal Fractures in 91 Consecutive Patients. Hand (N Y) 2019;15 (06):793-797. Doi: 10.1177/1558944719836235

5 Doarn MC, Nydick JA, Williams BD, Garcia MJ. Retrograde headless intramedullary screw fixation for displaced fifth metacarpal neck and shaft fractures: short term results. Hand (N Y) 2015;10(02): 314-318. Doi: 10.1007/s11552-014-9620-3

6 Kollitz KM, Hammert WC, Vedder NB, Huang JI. Metacarpal fractures: treatment and complications. Hand (N Y) 2014;9 (01):16-23. Doi: 10.1007/s11552-013-9562-1

7 del Piñal F, Moraleda E, Rúas JS, de Piero GH, Cerezal L. Minimally invasive fixation of fractures of the phalanges and metacarpals with intramedullary cannulated headless compression screws. J Hand Surg Am 2015;40(04):692-700. Doi: 10.1016/j. jhsa.2014.11.023

8 Henry SL. Discussion: Intramedullary Screw Fixation of Metacarpal Fractures Results in Excellent Functional Outcomes: A Literature Review. Plast Reconstr Surg 2019;143(04):1119-1121. Doi: $10.1097 /$ PRS.0000000000005487

9 Tobert DG, Klausmeyer M, Mudgal CS. Intramedullary Fixation of Metacarpal Fractures Using Headless Compression Screws. J Hand Microsurg 2016;8(03):134-139. Doi: 10.1055/s-00361593390

10 ten Berg PWL, Mudgal CS, Leibman MI, Belsky MR, Ruchelsman DE. Quantitative 3-dimensional CT analyses of intramedullary headless screw fixation for metacarpal neck fractures. J Hand Surg Am 2013;38(02):322-330.e2. Doi: 10.1016/j. jhsa.2012.09.029

11 Ruchelsman DE, Puri S, Feinberg-Zadek N, Leibman MI, Belsky MR. Clinical outcomes of limited-open retrograde intramedullary headless screw fixation of metacarpal fractures. J Hand Surg Am 2014;39(12):2390-2395. Doi: 10.1016/j. jhsa.2014.08.016

12 Warrender WJ, Ruchelsman DE, Livesey MG, et al. Low Rate of Complications Following Intramedullary Headless Compresion Screw Fixation of Metacarpal Fractures. Hand (N Y) 2019;15(06): 798-804. Doi: 10.1177/1558944719836214

13 Oh JR, Kim DS, Yeom JS, Kang SK, Kim YT. A comparative study of tensile strength of three operative fixation techniques for metacarpal shaft fractures in adults: A cadaver study. Clin Orthop Surg 2019;11(01):120-125. Doi: 10.4055/cios.2019.11.1.120

14 Hsu LP, Schwartz EG, Kalainov DM, Chen F, Makowiec RL. Complications of K-wire fixation in procedures involving the hand and 
wrist. J Hand Surg Am 2011;36(04):610-616. Doi: 10.1016/j. jhsa.2011.01.023

15 Cha SM, Shin HD, Kim YK. Comparison of low-profile locking plate fixation versus antegrade intramedullary nailing for unstable metacarpal shaft fractures-A prospective comparative study. Injury 2019;50(12):2252-2258. Doi: 10.1016/j.injury.2019.10.018
16 Melamed E, Joo L, Lin E, Perretta D, Capo JT. Plate Fixation versus Percutaneous Pinning for Unstable Metacarpal Fractures: A Metaanalysis. J Hand Surg Asian Pac Vol 2017;22(01):29-34. Doi: $10.1142 / \mathrm{S} 0218810417500058$ 